\title{
Measurement and Mapping of Maternal Health Service Coverage Through a Novel Composite Index: A Sub- National Level Analysis in India
}

\section{Tanvi Kiran}

Post Graduate Institute of Medical Education and Research

KP Junaid ( $\sim$ junaidkp222@gmail.com )

Post Graduate Institute of Medical Education and Research

Vineeth Rajagopal

Post Graduate Institute of Medical Education and Research

Madhu Gupta

Post Graduate Institute of Medical Education and Research

\section{Divya Sharma}

Post Graduate Institute of Medical Education and Research

\section{Research Article}

Keywords: Maternal Health, Service Coverage, Indian states, Composite index, Antenatal care, Intrapartum care, Postnatal care

Posted Date: January 4th, 2022

DOI: https://doi.org/10.21203/rs.3.rs-1188843/v1

License: (c) (i) This work is licensed under a Creative Commons Attribution 4.0 International License. Read Full License 


\section{Abstract}

Background: Expansion of maternal health service coverage is crucial for the survival and wellbeing of both mother and child. To date, limited literature exists on the measurement of maternal health service coverage at the subnational level in India. The prime objectives of the study were to comprehensively measure the maternal health service coverage by generating a composite index; map India by categorizing it into low, medium and high zones and examine its incremental changes over time.

Methods: Utilising a nationally representative time series data of 15 key indicators spread across three domains of antenatal care, intranatal care and postnatal care, we constructed a novel 'Maternal Health Service Coverage Index' (MHSI) for 29 states and 5 union territories of India for the base (2017-18) and reference (2019-20) years. Following a rigorous procedure, $\mathrm{MHSI}$ scores were generated using both arithmetic mean and geometric mean approach. We categorized India into low, medium and high maternal health coverage zones and further generated geospatial maps to examine the extent and transition of maternal health service coverage from base to reference year.

Results: India registered the highest mean percentage coverage (93.66\%) for 'institutional delivery' and lowest for 'treatment for obstetric complications' (9.25\%) among all the indicators. Depending on the usage of arithmetic mean and geometric mean approach, the maternal health service coverage index score for India exhibited marginal incremental change (between 0.015- 0.02 index points) in the reference year. West zone exhibited an upward transition in the coverage of maternal health service indicators, while none of the zones recorded a downward movement. States of Mizoram (east zone), Puducherry (south zone) showed a downward transition. Union territories of Dadra \& Nagar Haveli (west zone) and Chandigarh (north zone) along with the states of Maharashtra (west zone), Assam, as well as Jharkhand (both from the east \& north east zone), showed upward transition.

Conclusion: Overall, maternal health service coverage is increasing across India. Our study offers a novel summary measure to comprehensively quantify the coverage of maternal health service, which can momentously help India to identify lagged indicators and low performing regions, thereby warranting the targeted interventions and concentrated programmatic efforts to bolster the maternal health service coverage at the sub-national level.

\section{Background}

Reducing maternal mortality ratio is a pivotal target as part of the 'Sustainable Development Goal 3', which affirms 'to ensure healthy lives and promote wellbeing for all at all ages [1]. Maternal mortality is a crucial health indicator largely resulted from causes which are preventable and treatable [2]. Maternal health, which refers to the health status of a woman during the period of pregnancy, childbirth, and postpartum [3] has the potential of affecting significant maternal and child health outcomes, therefore the domain of maternal health assumes a pivotal role from the development perspective of a nation. Health system strengthening in terms of increased quality of care, health infrastructure, finance, and human resources can help bolster the maternal health service coverage, which in turn can have multiple positive implications on maternal, neonatal and child health statuses. Government of India has initiated many schemes and programmes to improve accessibility, affordability and quality of the maternal health service coverage across the country. [4-6]. Reaffirming its commitment towards achieving better maternal health outcomes, the Indian Government under the National Health Mission (NHM) introduced a novel strategic approach for 'Reproductive, Maternal, Newborn, Child and Adolescent Health (RMNCH+A)' [7]. This 'continuum of care' of $\mathrm{RMNCH}+\mathrm{A}$ refers to an integrated health service accessible to women, neonatal, infants or adolescents over the dimension of time (before pregnancy, during pregnancy, child birth and postnatal) and place (family and community care, outpatient and outreach services and hospital and health facilities) [8]. Maternal health, thus is one of the key 
thematic areas under the strategy of $\mathrm{RMNCH}+\mathrm{A}$, which aims to promote linkages between diverse health interventions to reduce maternal, neonatal and child mortality rates.

According to a guideline by the Indian Ministry of Health and Family Welfare (MoHFW), based on time dimension, the health care services for a pregnant woman are classified mainly into three types, namely; antenatal/ prenatal care, intranatal/intrapartum care, and postnatal/postpartum care [3]. Antenatal care (ANC) which refers to the systemic care and supervision recommended for women during her pregnancy, is largely a platform for preventive and promotive health care services. ANC primarily aims to monitor the progress of fetal growth and wellbeing of the mother and fetus, thereby facilitating facilitates for a timely management of the obstetric complications. MoHFW guidelines recommends a minimum of four ANC visits in which the ANC registration and first ANC checkup within the first trimester (within 12 weeks) is accorded a high priority [3]. The World Health Organization (WHO) recommends various interventions ranging from dietary counselling, nutrient supplementation and a number of essential screening tests to improve the utilization and quality of antenatal care [9]. Another important stage of care in the continuum of RMNCH+A is the intranatal/ intrapartum care (INC), which refers to systemic care to a pregnant women during labour and delivery [3]. The time of birth is considered to be extremely crucial for both mother and the child as the chances of complication is high during this stage [10]. Sufficient literary evidence supports the prevalence of high-risk pregnancy and pre-term birth among the Indian and other south Asian population [11-15]. Therefore, the delivery of the baby crucially requires an appropriate setting, where lifesaving equipment is available and hygienic conditions are fully maintained. Utilization of public, private or charitable trust/Non-Governmental Organization health facility during the labour and child birth, referred as Institutional delivery, is a significant mean to timely management of obstetric complications [16]. However, literature reported that a considerable proportion still deliver at home in India attributed to social, cultural, physical and financial factors [17]. Increased skilled birth attendant(SBA) coverage is associated with reduced probability of maternal deaths [16] especially for those women who prefers to deliver at home in India. The third stage of care is the postnatal/postpartum care (PNC), which involves systemic care of women after delivery, where the first 42 days ( 6 weeks) is conventionally treated as the postpartum period [3]. MoHFW guideline recommends at least three postnatal visits to the health facility after an uncomplicated normal institutional delivery in India. Evidence indicates that larger proportion of the total neonatal deaths occurs in the first week of postnatal with highest number in the first three days [18].

Till date limited literature exists on measurement of maternal health service coverage at sub-national level in India. Prior research mainly focussed on the theme of Reproductive, Maternal, New born and Child Health (RMNCH) service coverage and their inequities at national and sub-national level in India. Majority of them used Coverage Gap Index (CGI) as an outcome measure of the RMNCH service coverage, which is primarily constituted by the domains of reproductive services, maternal and new born care, immunization and management of illness [19-21]. However, there were only two indicators namely 'skilled birth attendant' and 'antenatal care coverage' under the domain of maternal and new born care, which makes the measurement of maternal health service coverage narrow and incomplete. To the best of our knowledge, no published study has estimated and examined the maternal health service coverage using a composite index. The present study addresses this lacuna by constructing a comprehensive 'Maternal Health Service coverage Index' (MHSI), which includes cumulative set of relatively large maternal health indicators categorized into three domains of antenatal, intranatal and postnatal care coverage, which is a major highlight of the study. Further, the constructed MHSI has been used for the identification of the low, medium and high coverage regions across different time series points in India, a theme which was largely unexplored in the previous studies. In this backdrop, utilising a nationally representative data, the specific objectives of the study are; a) to comprehensively measure maternal health service coverage at sub-national level in India by constructing a composite index using a rigorous methodology; b) to map and categorize India into low, medium and high maternal health coverage zones; c) 
to examine the sub- national areas (states and union territories of India) which have transitioned from low to higher category of coverage and vice versa across the different time points.

\section{Methods}

\section{Data source}

The study extracted secondary data for three financial years (2017-2018 to 2019-20) on various health indicators of maternal health service coverage from the Health Management Information System (HMIS) portal, an initiative under National Health Mission (NHM) by the Government of India. HMIS is free of cost publicly available web-based routine monitoring system of the vital Reproductive Maternal Newborn Child Health (RMNCH) data uploaded by the States and Union Territories (UT) in India. The HMIS portal that provides annual data on financial year basis has been reporting detailed data at sub-national level since the year 2017. A total of 29 states and 5 UTs have been included for examining maternal health service coverage at sub-national level in India during the period 2017-2018 (base year) and 2019-2020 (reference year). The Indian states and union territories under the study have also been classified into four geographical zones namely north, west, east \& north east and south [22]. The raw and coded data has also been uploaded on Mendeley data repository [23] to provide free and unrestricted access to this time series data for facilitating transparency and reproducibility of the results.

\section{Selection and classification of Indicators}

The key HMIS indicators at sub-national level is segregated in to different domains namely child health, family planning, maternal health and the 'other' miscellaneous. Since, the present study aimed to construct composite indicator for maternal health service coverage at state and UT level, therefor the individual indicators have been selected from the domain of maternal health based on the opinion of medical experts and public health professionals along with extensive review of literature. The experts mainly considered relevance, usefulness, importance, and distinctiveness of the indicators in valuation of the maternal health service coverage. In consensus with the experts, the study finalized 15 individual indicators to compute the Maternal Health Service Coverage Index (MHSI). It is to be noted that because of the difference in population composition and territory of Indian states, it was not be appropriate to choose the indicators reported in the absolute values for the construction of maternal health service coverage. Hence, the study considered the relative measure of the selected indicators for the purpose of index construction.

The selected indicators were further classified under the 3 domains of Antenatal care (ANC) coverage, Intranatal care (INC) Coverage and Postnatal care (PNC) coverage based on various guidelines by WHO and Ministry of Health and family Welfare $[3,9,10,18]$. Furthermore, the study classified the component indicators of ANC coverage domain in to 3 sub-domains namely 'ANC registration \& check-ups (ANC1)', 'Supplementation \& prophylaxis in pregnancy (ANC2)', and 'Essential screening tests (ANC3)'. The detailed description of the maternal health service coverage indicators has been given in the Table 1.

Table 1: Operational definitions of indicators for Maternal Health Service Coverage Index (MHSI). 


\section{Domain I: Antenatal Care (ANC) Coverage}

ANC sub-domain I: ANC Registration \& check-up (ANC1)
1. ANC Registration (ANC1_1)
Percentage first Trimester registration to Total ANC Registrations.
Percentage Pregnant Woman Total ANC Registrations.

1. ANC Check-ups (ANC1_2)
Number of pregnant women registered for ANC within first trimester.

Number of Pregnant Woman received 4 ANC check-ups
Total number of pregnant women registered for ANC.

Total number of pregnant women registered for ANC.

ANC sub-domain II: Supplementation \& prophylaxis in pregnancy (ANC2)

1. Immunization against Tetanus (ANC211)
Percentage Pregnant women received TT2+ TT Booster to Total ANC Registration.
Number of pregnant women received TT2+ TT Booster
Total number of pregnant women registered for ANC.

Total number of pregnant women registered for ANC.
Number of pregnant women having severe Anaemia $(\mathrm{Hb}<7)$ treated at institution.

Number of pregnant women given 360 Calcium tablets.

Total number of pregnant women registered for ANC.

Total number of pregnant women registered for ANC.

Number of pregnant women given one Albendazole tablet after 1 st trimester
Total number of pregnant women registered for ANC.
ANC sub-domain III: Essential screening tests (ANC3)

1. Screening for Diabetes (ANC3_1) Percentage Pregnant women tested for blood sugar using OGTT to Total ANC Registration after 1 st trimester to Total ANC Registration.

$$
\text { OGTT to Total ANC Registration }
$$

Percentage Pregnant women Deworming
(ANC2_5)
Percentage Pregnant women

1. Screening for Syphilis (ANC3_2) tested for Syphilis to Total ANC Registration
Number of Pregnant women tested for blood sugar using OGTT.

Number of Pregnant women tested for Syphilis.
Total number of pregnant women registered for ANC.

Total number of pregnant women registered for ANC. 

1. Screening for HIV (ANC3_3)
Percentage Female screened for
HIV to Total ANC Registration.
Number of females
screened for HIV

Total number of pregnant women registered for ANC.

\section{Domain II: Intranatal care (INC) coverage}

\begin{tabular}{|c|c|c|c|}
\hline $\begin{array}{l}\text { 1. SBA attended } \\
\text { home deliveries } \\
\text { (INC_1) }\end{array}$ & $\begin{array}{l}\text { Percentage SBA attended home } \\
\text { deliveries to Total Reported } \\
\text { Home Deliveries }\end{array}$ & $\begin{array}{l}\text { Number of home } \\
\text { deliveries attended by } \\
\text { SBA trained (Doctor/ } \\
\text { Nurse/ ANM) }\end{array}$ & $\begin{array}{l}\text { Total number } \\
\text { of home } \\
\text { deliveries } \\
\text { reported. }\end{array}$ \\
\hline $\begin{array}{l}\text { 1. Institutional } \\
\text { delivery (INC_2) }\end{array}$ & $\begin{array}{l}\text { Percentage Institutional } \\
\text { deliveries to Total Reported } \\
\text { Deliveries }\end{array}$ & $\begin{array}{l}\text { Number of deliveries } \\
\text { conducted in both public } \\
\text { and private institution. }\end{array}$ & $\begin{array}{l}\text { Total number } \\
\text { of reported } \\
\text { deliveries. }\end{array}$ \\
\hline $\begin{array}{l}\text { 1. C-Section } \\
\text { deliveries } \\
\text { (INC_3) }\end{array}$ & $\begin{array}{l}\text { Percentage C-section deliveries } \\
\text { (Public + Pvt.) to reported } \\
\text { institutional (Public + Pvt.) } \\
\text { deliveries }\end{array}$ & $\begin{array}{l}\text { Number of C-section } \\
\text { deliveries conducted in } \\
\text { both public and private } \\
\text { institution. }\end{array}$ & $\begin{array}{l}\text { Total number } \\
\text { of reported } \\
\text { institutional } \\
\text { deliveries. }\end{array}$ \\
\hline $\begin{array}{l}\text { 1. Treatment for } \\
\text { obstetric } \\
\text { complications } \\
\text { (INC_4) }\end{array}$ & $\begin{array}{l}\text { Percentage cases of Pregnant } \\
\text { women with Obstetric } \\
\text { Complications and attended to } \\
\text { reported deliveries }\end{array}$ & $\begin{array}{l}\text { Number of Pregnant } \\
\text { women with Obstetric } \\
\text { Complications and } \\
\text { attended. }\end{array}$ & $\begin{array}{l}\text { Total number } \\
\text { of reported } \\
\text { deliveries. }\end{array}$ \\
\hline \multicolumn{4}{|c|}{ Domain III: Postnatal care (PNC) coverage } \\
\hline $\begin{array}{l}\text { 1. Postpartum } \\
\text { check-up } \\
\text { (PNC_1) }\end{array}$ & $\begin{array}{l}\text { Percentage women getting } 1 \text { st } \\
\text { postpartum checkup between } 48 \\
\text { hours and } 14 \text { days to total } \\
\text { reported deliveries }\end{array}$ & $\begin{array}{l}\text { Number of women } \\
\text { getting } 1 \text { st postpartum } \\
\text { checkup between } 48 \\
\text { hours and } 14 \text { days. }\end{array}$ & $\begin{array}{l}\text { Total number } \\
\text { of reported } \\
\text { deliveries. }\end{array}$ \\
\hline
\end{tabular}

\section{Data cleaning, Data quality, consistency checking}

Five percent of the obtained data on the selected indicators of maternal health service coverage were randomly chosen and rechecked for the errors in the data entry [24]. A zero-error rate was observed. Followed by that, the data was checked for the missing values. Due to availability of data for 3 financial years only, the standard imputation techniques and extrapolation and interpolation techniques could not be applied to treat the missing values [25]. The states or UTs with missing values for more than one specific year on any indicator, have been excluded from the study. As per this criterion, Daman \& Diu and Lakshadweep were removed from the study. The states/UTs having missing values only for one particular year were replaced by the available values of most recent year [26].

\section{Computation of Maternal Health Service-coverage Index (MHSI)}

\section{Data normalization}

The extracted data on selected Maternal Health Service Coverage Index (MHSI) from the HMIS were subjected to normalization based on the 'Minimum-Maximum approach' used by United Nations Development Programme (UNDP) for the computation of Human Development Index (HDI) values. Each of the selected 15 indicators are positive in nature, where the resultant higher index value shall represent the positive result (higher the value, better the maternal 
health service coverage). Owing to "higher the better" nature of the individual values, the said data was normalised using the following formula [27]:

$$
N_{i}=\frac{\left(A_{i}-L_{i}\right)}{\left(U_{i}-L_{i}\right)}
$$

Where, $N_{i}$ is the normalised value of the $i^{t h}$ indicator, $A_{i}$ represents the Actual value of the $i^{\text {th }}$ indicator, $U_{i}$ and $L_{i}$ denote the maximum and minimum values (goal posts) of the dimension indicators respectively. The UNDP in of its reports [28], recommended the use of absolute goal posts over the observed goal posts in the normalization process. The study fixed 100\% (aspirational goal) and $0 \%$ (natural zero) as the maximum and minimum value (goal posts) respectively, from which the individual indicators were standardised.

\section{Construction of MHSI: Different scenarios}

Followed by the calculation of normalized individual indicators, the Maternal Health Service Coverage Index (MHSI) involves three detailed steps. The first step was to estimate three sub-indices of the ANC that is ANC1, ANC2 and ANC3 and to estimate separate indices of INC and PNC. Since both domains of INC and PNC coverage have not been segregated further, the study directly computed INC and PNC index from its individual indicators. Followed by the step 1, the study computed ANC index from its three subindices. Finally in step 3, the study aggregated ANC, INC and PNC indices to compute a comprehensive cumulative index for 'Maternal Health Service Coverage'. The study employed four alternate scenarios using the aforementioned three steps for the computation of MHSI. The different scenarios have been explained in detail in the Figure 1. Alternate scenarios differ by the choice of aggregation method, i.e., usage of use arithmetic mean approach and geometric mean approach [28], which is primarily based on procedure followed for construction of Human Development Index (HDI) by United Nations Development Programme (UNDP). Microsoft office Excel 2019 and IBM SPSS version 24 was employed for construction of index and computation of related descriptive statistical measures.

\section{Categorization and mapping of Indian states and Union Territories}

The index values of the MHSI ranges between 0 and 1, where values close to 1 indicate high maternal service coverage and value close to zero correspond to low coverage. Furthermore, the study categorized Indian states in to low, medium, and high categories based on the MHSI score. The study considered the period 2017-2018 as the base year and calculated $33^{\text {rd }}$ and $66^{\text {th }}$ percentile score of the MHSI values of Indian states. This percentile values were used as the criteria for determining the category the Indian state belonged to. The Indian state with MHSI value below

$33^{\text {rd }}$ percentile categorised to low category, those with above $66^{\text {th }}$ percentile was categorised to high category and the ones having score between $33^{\text {rd }}$ and $66^{\text {th }}$ percentile was assigned the medium category. The study categorised Indian states based on MHSI values in four alternate scenarios under study. The details of the $33^{\text {rd }}$ and $66^{\text {th }}$ percentile score in different scenarios have been described in the Additional file 1. Furthermore, the study geo-spatially mapped the Indian states into different MHSI zones using the Arch GIS 10.8 software.

\section{Results}

\section{Descriptive characteristics of maternal health service coverage indicators}


Table 2 and Figure 2 describes the characteristics of selected maternal health service coverage indicators at regional and national level. Out of the 15 indicators, institutional delivery showed the highest mean percentage across India and every region. The study observed that on an average, $93.66 \%$ of the total reported delivery delivered at institution (both public and private) in India. Across India, 'treatment for obstetric complications' was observed to be the lowest (9.25\%) among all the indicators.

In most of the indicators, performance of south zone and west zone was notable. Of the 4 zones, the south zone recorded highest mean percentage coverage for ANC check-ups (88.365), IFA supplementation (91.31\%), institutional deliveries (99.79\%), screening for diabetes (33.24\%), screening for HIV (69.09\%), SBA attended home deliveries (46.63\%), c-section deliveries (38.59\%), postpartum check-up (67.64\%) and treatment for obstetric complications (13.91\%). In contrast, the west zone registered highest mean percentage coverage for ANC registration (78.12\%), immunization against tetanus (86.89\%), anemia treatment coverage (75.02\%), calcium supplementation (77.33\%), deworming (59.71\%) and screening for syphilis (56.35\%). East \& north east zone registered the lowest mean percentage coverage in 10 out of 15 indicators namely, ANC registration (63.95\%), ANC check-up (60.25\%), IFA supplementation (59.25), anemia treatment coverage (52.63\%), calcium supplementation (36.51\%), deworming (25.78\%), screening for diabetes (14.05\%), institutional delivery (88.62\%), c-section delivery (21\%) and treatment for obstetric complications (6.13\%).

On the other hand, north zone registered lowest mean percentage coverage for immunization against tetanus (73.58\%), screening for HIV (37.89\%), SBA attended home deliveries (17.30\%) and postpartum check-up (54.71\%). Among the indicators, none of the zones recorded more than $50 \%$ coverage in screening for diabetes, SBA attended home deliveries, c-section deliveries and treatment for obstetric complication. Furthermore, estimates of the coefficient of variation showed indicator of 'institutional delivery' has the lowest and the indicator of 'the screening for diabetes' has the highest variations in India. 
Table 2

Descriptive characteristics of indicators of maternal health service coverage at regional and national level over a span of three years (2017-18 to 2019-20)

Indicators

\section{Mean (\%)}

$\begin{array}{llll}\text { North } & \text { West } & \text { East } & \text { South India } \\ \text { zone } & \text { zone } & \begin{array}{l}\text { \& } \\ \text { north } \\ \text { east } \\ \end{array} & \text { zone } \\ & & \end{array}$

Coefficient of variation (\%)

North West East \& South India zone zone north zone

east

zone

Domain I: Antenatal Care Coverage (ANC)

ANC Sub-domain I: ANC Registration \& check-up (ANC1)

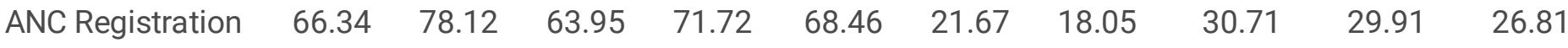

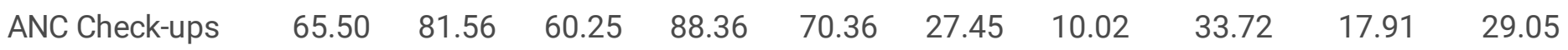

ANC Sub-domain II: Supplementation \& prophylaxis in pregnancy (ANC2)

$\begin{array}{lllllllllll}\text { Immunization } & 73.58 & 86.89 & 74.98 & 82.66 & 78.07 & 27.45 & 21.83 & 22.28 & 35.89 & 27.04\end{array}$

against Tetanus

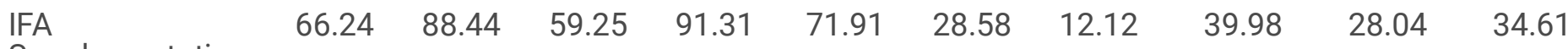

Supplementation

Anaemia

treatment

$\begin{array}{llllllllll}65.73 & 75.02 & 52.63 & 56.04 & 60.65 & 22.79 & 21.94 & 39.39 & 33.13 & 32.79\end{array}$

coverage

Calcium

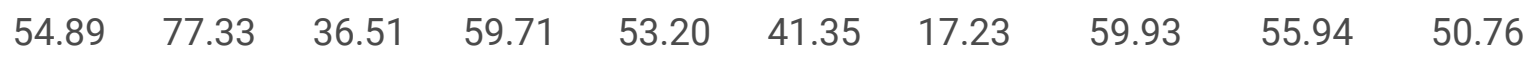

supplementation

Deworming

$32.89 \quad 59.71$

25.78

31.72

34.70

63.83

33.22

79.81

69.43

68.52

ANC Sub-domain III: Essential screening tests (ANC3)

$\begin{array}{lcccccccccc}\begin{array}{l}\text { Screening for } \\ \text { Diabetes }\end{array} & 16.89 & 20.74 & 14.05 & 33.24 & 19.37 & 97.18 & 120.45 & 151.51 & 135.87 & 140.00 \\ \begin{array}{l}\text { Screening for } \\ \text { Syphilis }\end{array} & 42.86 & 56.35 & 36.99 & 35.21 & 41.64 & 47.61 & 92.80 & 59.51 & 53.63 & 70.60 \\ \begin{array}{l}\text { Screening for } \\ \text { HIV }\end{array} & 37.89 & 64.64 & 45.41 & 69.09 & 50.99 & 58.58 & 81.32 & 81.81 & 48.54 & 74.68 \\ \end{array}$

Domain II: Intranatal care coverage (INC)

\begin{tabular}{|c|c|c|c|c|c|c|c|c|c|c|}
\hline $\begin{array}{l}\text { SBA attended } \\
\text { home deliveries }\end{array}$ & 17.30 & 30.51 & 29.61 & 46.63 & 30.10 & 80.29 & 64.49 & 67.46 & 50.23 & 69.73 \\
\hline $\begin{array}{l}\text { Institutional } \\
\text { delivery }\end{array}$ & 93.76 & 98.29 & 88.62 & 99.79 & 93.66 & 5.17 & 2.11 & 12.20 & 0.30 & 9.00 \\
\hline $\begin{array}{l}\text { C-Section } \\
\text { deliveries }\end{array}$ & 24.04 & 23.04 & 21.00 & 38.59 & 25.27 & 48.85 & 47.94 & 44.93 & 18.17 & 46.45 \\
\hline $\begin{array}{l}\text { Treatment for } \\
\text { obstetric } \\
\text { complications }\end{array}$ & 11.76 & 7.60 & 6.13 & 13.91 & 9.25 & 79.76 & 43.73 & 69.20 & 121.21 & 101.92 \\
\hline
\end{tabular}




\begin{tabular}{|c|c|c|c|c|c|c|c|c|c|c|}
\hline \multirow[t]{2}{*}{ Indicators } & \multicolumn{5}{|c|}{ Mean (\%) } & \multicolumn{5}{|c|}{ Coefficient of variation (\%) } \\
\hline & $\begin{array}{l}\text { North } \\
\text { zone }\end{array}$ & $\begin{array}{l}\text { West } \\
\text { zone }\end{array}$ & $\begin{array}{l}\text { East } \\
\& \\
\text { north } \\
\text { east } \\
\text { zone }\end{array}$ & $\begin{array}{l}\text { South } \\
\text { zone }\end{array}$ & India & $\begin{array}{l}\text { North } \\
\text { zone }\end{array}$ & $\begin{array}{l}\text { West } \\
\text { zone }\end{array}$ & $\begin{array}{l}\text { East \& } \\
\text { north } \\
\text { east } \\
\text { zone }\end{array}$ & $\begin{array}{l}\text { South } \\
\text { zone }\end{array}$ & India \\
\hline $\begin{array}{l}\text { Postpartum } \\
\text { Check-up }\end{array}$ & 54.71 & 59.01 & 61.23 & 67.64 & 60.24 & 53.21 & 37.36 & 36.89 & 65.33 & 48.09 \\
\hline
\end{tabular}

Composite Maternal Health Service Coverage Index (MHSI) and its comparison between base year and reference year

The study computed MHSI using different methodological based scenarios already explained in the figure 1. The MHSI values based on four different approaches for the base year (2017-2018) and reference year (2019-2020) have been presented in the Additional file 2. In scenario I, all the sub-indices and domain indices of MHSI were aggregated through arithmetic mean approach, whereas in the Scenario IV, the geometric mean approach was employed [28]. For conciseness, MHSI values across base year and reference year were compared only for scenarios I (Table 3) and IV (Table 4). However, in the interest of large audience, details of MHSI values across base and reference year for the scenario II and III have also been presented in Additional file 3 and 4, nevertheless these tables do not form the part of analytic inferences of the present study.

For scenario I (Table 3), the MHSI of India increased slightly from base year (0.523) to the reference year (0.538), however both values corresponded to medium level of maternal health service coverage. At regional level, MHSI value of west zone showed highest incremental change of about 0.049 index points, which transitioned it from the category of medium MHSI in base year to high MHSI level in the reference year. In contrast, there is negative change in value of MHSI (-0.042) of south zone, but it still remained under the category of high MHSI value. Overall, state of Kerala (South zone) topped both in the base and reference year with MHSI scores of 0.858 and 0.748 , respectively. Rajasthan (North zone) with an MHSI score of 0.309 and Arunachal Pradesh (East \& north east zone) with a score of 0.337 were in the last position for base year and reference year, respectively. The states/UTs namely, Dadra \& Nagar Haveli (0.663), Goa (0.66) and Maharashtra (0.588) from west zone and Assam (0.626) from east zone transitioned upwards from medium to high category in the reference year, while others Chandigarh (0.470) and Delhi (0.439) from north zone as well as Jharkhand (0.467) from east zone moved upwards from low to medium category. Only the states of Mizoram (0.346) of east zone and Puducherry (0.388) of south zone showed a downward transition, from medium to low MHSI category. The state of Uttar Pradesh (0.119) from north zone and the UT of Dadra \& Nagar Haveli (0.107) from west zone showed highest positive increment in MHSI value. While, the highest negative decrement recorded by the state of Mizoram (-0.135) and UT of Puducherry $(-0.158)$. 
Table 3

Incremental change of MHSI values and categorization of states in base year and reference year (Scenario I)

\begin{tabular}{|c|c|c|c|c|c|c|}
\hline \multirow[t]{2}{*}{ State/UTs } & \multicolumn{2}{|c|}{$\begin{array}{l}\text { MHSI Values } \\
\text { in Base Year (2017- } \\
18)\end{array}$} & \multicolumn{2}{|c|}{$\begin{array}{l}\text { MHSI Values } \\
\text { in Reference year } \\
(2019-20)\end{array}$} & \multicolumn{2}{|c|}{ Incremental Changes in MHSI } \\
\hline & $\begin{array}{l}\text { Index } \\
\text { value }\end{array}$ & Category & $\begin{array}{l}\text { Index } \\
\text { value }\end{array}$ & Category & $\begin{array}{l}\text { Change in } \\
\text { value }\end{array}$ & $\begin{array}{l}\text { Change in } \\
\text { category }\end{array}$ \\
\hline North zone & 0.462 & Medium & 0.502 & Medium & 0.04 & $\rightarrow$ \\
\hline Chandigarh* & 0.370 & Low & 0.470 & Medium & 0.100 & $\uparrow$ \\
\hline Delhi* & 0.437 & Low & 0.439 & Medium & 0.002 & $\uparrow$ \\
\hline Haryana & 0.549 & Medium & 0.530 & Medium & -0.019 & $\leftarrow$ \\
\hline Himachal Pradesh & 0.608 & High & 0.699 & High & 0.090 & $\rightarrow$ \\
\hline Jammu\& Kashmir & 0.505 & Medium & 0.499 & Medium & -0.006 & $\leftarrow$ \\
\hline Punjab & 0.645 & High & 0.663 & High & 0.018 & $\rightarrow$ \\
\hline Rajasthan & 0.309 & Low & 0.345 & Low & 0.036 & $\rightarrow$ \\
\hline Uttar Pradesh & 0.318 & Low & 0.436 & Low & 0.119 & $\rightarrow$ \\
\hline Uttarakhand & 0.419 & Low & 0.433 & Low & 0.015 & $\rightarrow$ \\
\hline West zone & 0.530 & Medium & 0.579 & High & 0.049 & $\uparrow$ \\
\hline Chhattisgarh & 0.597 & High & 0.572 & High & -0.025 & $\leftarrow$ \\
\hline Dadra \& Nagar Haveli* & 0.556 & Medium & 0.663 & High & 0.107 & $\uparrow$ \\
\hline Goa & 0.564 & Medium & 0.660 & High & 0.096 & $\uparrow$ \\
\hline Gujarat & 0.568 & High & 0.654 & High & 0.086 & $\rightarrow$ \\
\hline Madhya Pradesh & 0.356 & Low & 0.337 & Low & -0.019 & $\leftarrow$ \\
\hline Maharashtra & 0.540 & Medium & 0.588 & High & 0.048 & $\uparrow$ \\
\hline East \& north east zone & 0.478 & Medium & 0.491 & Medium & 0.013 & $\rightarrow$ \\
\hline $\begin{array}{l}\text { Andaman \& Nicobar } \\
\text { Island* }\end{array}$ & 0.644 & High & 0.669 & High & 0.025 & $\rightarrow$ \\
\hline Arunachal Pradesh & 0.378 & Low & 0.337 & Low & -0.042 & $\leftarrow$ \\
\hline Assam & 0.533 & Medium & 0.626 & High & 0.093 & $\uparrow$ \\
\hline Bihar & 0.334 & Low & 0.369 & Low & 0.035 & $\rightarrow$ \\
\hline Jharkhand & 0.410 & Low & 0.467 & Medium & 0.057 & $\uparrow$ \\
\hline
\end{tabular}

Note: $\uparrow$ Upward transition from a lower category to higher; $\rightarrow$ No change in category, but MHSI value increased; $\rightarrow$ No change in category but MHSI value decreased; $\downarrow$ Downward transition from a higher category to lower.

*Denotes Union Territory (UT). 


\begin{tabular}{|c|c|c|c|c|c|c|}
\hline \multirow[t]{3}{*}{ State/UTs } & \multirow{2}{*}{\multicolumn{2}{|c|}{$\begin{array}{l}\text { MHSI Values } \\
\text { in Base Year (2017- } \\
\text { 18) }\end{array}$}} & \multirow{2}{*}{\multicolumn{2}{|c|}{$\begin{array}{l}\text { MHSI Values } \\
\text { in Reference year } \\
(2019-20)\end{array}$}} & \multirow{2}{*}{\multicolumn{2}{|c|}{ Incremental Changes in MHSI }} \\
\hline & & & & & & \\
\hline & $\begin{array}{l}\text { Index } \\
\text { value }\end{array}$ & Category & $\begin{array}{l}\text { Index } \\
\text { value }\end{array}$ & Category & $\begin{array}{l}\text { Change in } \\
\text { value }\end{array}$ & $\begin{array}{l}\text { Change in } \\
\text { category }\end{array}$ \\
\hline Manipur & 0.438 & Low & 0.426 & Low & -0.012 & $\leftarrow$ \\
\hline Meghalaya & 0.340 & Low & 0.340 & Low & 0.000 & $\rightarrow$ \\
\hline Mizoram & 0.481 & Medium & 0.346 & Low & -0.135 & $\downarrow$ \\
\hline Nagaland & 0.371 & Low & 0.372 & Low & 0.001 & $\rightarrow$ \\
\hline Odisha & 0.591 & High & 0.692 & High & 0.101 & $\rightarrow$ \\
\hline Sikkim & 0.629 & High & 0.628 & High & -0.001 & $\leftarrow$ \\
\hline Tripura & 0.479 & Medium & 0.504 & Medium & 0.025 & $\rightarrow$ \\
\hline West Bengal & 0.584 & High & 0.614 & High & 0.030 & $\rightarrow$ \\
\hline South zone & 0.620 & High & 0.578 & High & -0.042 & $\leftarrow$ \\
\hline Andhra Pradesh & 0.605 & High & 0.660 & High & 0.055 & $\rightarrow$ \\
\hline Karnataka & 0.712 & High & 0.723 & High & 0.012 & $\rightarrow$ \\
\hline Kerala & 0.858 & High & 0.748 & High & -0.110 & $\leftarrow$ \\
\hline Puducherry* & 0.546 & Medium & 0.388 & Low & -0.158 & $\downarrow$ \\
\hline Tamil Nadu & 0.462 & Medium & 0.476 & Medium & 0.015 & $\rightarrow$ \\
\hline Telangana & 0.540 & Medium & 0.472 & Medium & -0.068 & $\leftarrow$ \\
\hline India & 0.523 & Medium & 0.538 & Medium & 0.015 & $\rightarrow$ \\
\hline \multicolumn{7}{|c|}{$\begin{array}{l}\text { Note: } \uparrow \text { Upward transition from a lower category to higher; } \rightarrow \text { No change in category, but MHSI value increased; }- \\
\text { No change in category but MHSI value decreased; } \downarrow \text { Downward transition from a higher category to lower. }\end{array}$} \\
\hline \multicolumn{7}{|c|}{ * Denotes Union Territory (UT). } \\
\hline
\end{tabular}

For scenario IV (Table 4), which is based on geometric mean approach, the MHSI value for India had marginally increased (by 0.015 index points) in the reference year (0.377) as compared to base year (0.358). India has remained in the medium category, thereby indicating no upward or downward transition with respect to maternal health service coverage. In terms of absolute index values, highest increment in MHSI score (0.046 index points) was achieved by north zone $(0.362)$ in the reference year, however it remained in the medium category only. West zone is the only region, which transitioned from medium to high MHSI category in the reference year, and it recorded the highest MHSI value of 0.427 followed by south zone (0.389). Apart from south zone, MHSI index scores increased for all other zones in the reference year. The study observed an upward transition of MHSI category from low to medium in the following Indian states/UTs namely Chandigarh (0.331) and Uttar Pradesh (0.316) from north zone and Jharkhand (0.332) from east \& north east zone, while Dadra \& Nagar Haveli (0.477), Gujarat (0.49) and Maharashtra (0.477) from west zone and Assam (0.478) from east $\&$ north east zone showed an upward transition in category from medium to high. 
Only two states, Mizoram (0.248) from east \& north east zone and Puducherry (0.331) from south zone showed a downward transition in MHSI category. The state of Mizoram transitioned from medium to low category while that for the UT of Puducherry was from High to Medium category. The state of Goa (0.125) and UT of Chandigarh (0.148) recorded highest positive incremental change in MHSI value whereas, the state of Mizoram (-0.073) and UT of Puducherry (-0.135) registered highest negative decrement. 
Table 4

Incremental change of MHSI values and categorization of states in base year and reference year (Scenario IV)

\begin{tabular}{|c|c|c|c|c|c|c|}
\hline \multirow[t]{2}{*}{ State/UTs } & \multicolumn{2}{|c|}{$\begin{array}{l}\text { MHSI Values } \\
\text { in Base Year } \\
(2017-18)\end{array}$} & \multicolumn{2}{|c|}{$\begin{array}{l}\text { MHSI Values } \\
\text { in Reference year } \\
(2019-20)\end{array}$} & \multicolumn{2}{|c|}{ Incremental Changes in MHSI } \\
\hline & $\begin{array}{l}\text { Index } \\
\text { value }\end{array}$ & Category & $\begin{array}{l}\text { Index } \\
\text { value }\end{array}$ & Category & $\begin{array}{l}\text { Change in } \\
\text { value }\end{array}$ & $\begin{array}{l}\text { change in } \\
\text { category }\end{array}$ \\
\hline North zone & 0.315 & Medium & 0.362 & Medium & 0.046 & $\rightarrow$ \\
\hline Chandigarh* & 0.183 & Low & 0.331 & Medium & 0.148 & $\uparrow$ \\
\hline Delhi* & 0.332 & Medium & 0.312 & Medium & -0.020 & $\leftarrow$ \\
\hline Haryana & 0.404 & Medium & 0.398 & Medium & -0.006 & $\leftarrow$ \\
\hline Himachal Pradesh & 0.483 & High & 0.575 & High & 0.092 & $\rightarrow$ \\
\hline Jammu\& Kashmir & 0.342 & Medium & 0.376 & Medium & 0.034 & $\rightarrow$ \\
\hline Punjab & 0.504 & High & 0.545 & High & 0.041 & $\rightarrow$ \\
\hline Rajasthan & 0.234 & Low & 0.224 & Low & -0.009 & $\leftarrow$ \\
\hline Uttar Pradesh & 0.211 & Low & 0.316 & Medium & 0.105 & $\uparrow$ \\
\hline Uttarakhand & 0.307 & Medium & 0.311 & Medium & 0.005 & $\rightarrow$ \\
\hline West zone & 0.393 & Medium & 0.427 & High & 0.034 & $\uparrow$ \\
\hline Chhattisgarh & 0.504 & High & 0.469 & High & -0.035 & $\leftarrow$ \\
\hline Dadra \& Nagar Haveli* & 0.412 & Medium & 0.477 & High & 0.065 & $\uparrow$ \\
\hline Goa & 0.430 & High & 0.555 & High & 0.125 & $\rightarrow$ \\
\hline Gujarat & 0.402 & Medium & 0.490 & High & 0.088 & $\uparrow$ \\
\hline Madhya Pradesh & 0.241 & Low & 0.207 & Low & -0.034 & $\leftarrow$ \\
\hline Maharashtra & 0.422 & Medium & 0.477 & High & 0.055 & $\uparrow$ \\
\hline East\& north east zone & 0.324 & Medium & 0.337 & Medium & 0.013 & $\rightarrow$ \\
\hline $\begin{array}{l}\text { Andaman \& Nicobar } \\
\text { Island* }\end{array}$ & 0.528 & High & 0.532 & High & 0.004 & $\rightarrow$ \\
\hline Arunachal Pradesh & 0.289 & Low & 0.252 & Low & -0.036 & $\leftarrow$ \\
\hline Assam & 0.384 & Medium & 0.478 & High & 0.094 & $\uparrow$ \\
\hline Bihar & 0.201 & Low & 0.231 & Low & 0.030 & $\rightarrow$ \\
\hline Jharkhand & 0.277 & Low & 0.332 & Medium & 0.055 & $\uparrow$ \\
\hline
\end{tabular}

Note: $\uparrow$ Upward transition from a lower category to higher; $\rightarrow$ No change in category but MHSI value increased; $\rightarrow$ No change in category but MHSI value decreased; $\downarrow$ Downward transition from a higher category to lower.

*Denotes Union Territory (UT). 


\begin{tabular}{|c|c|c|c|c|c|c|}
\hline \multirow[t]{3}{*}{ State/UTs } & \multirow{2}{*}{\multicolumn{2}{|c|}{$\begin{array}{l}\text { MHSI Values } \\
\text { in Base Year } \\
(2017-18)\end{array}$}} & \multirow{2}{*}{\multicolumn{2}{|c|}{$\begin{array}{l}\text { MHSI Values } \\
\text { in Reference year } \\
(2019-20)\end{array}$}} & \multirow{2}{*}{\multicolumn{2}{|c|}{ Incremental Changes in MHSI }} \\
\hline & & & & & & \\
\hline & $\begin{array}{l}\text { Index } \\
\text { value }\end{array}$ & Category & $\begin{array}{l}\text { Index } \\
\text { value }\end{array}$ & Category & $\begin{array}{l}\text { Change in } \\
\text { value }\end{array}$ & $\begin{array}{l}\text { change in } \\
\text { category }\end{array}$ \\
\hline Manipur & 0.310 & Medium & 0.305 & Medium & -0.005 & $\leftarrow$ \\
\hline Meghalaya & 0.258 & Low & 0.266 & Low & 0.008 & $\rightarrow$ \\
\hline Mizoram & 0.321 & Medium & 0.248 & Low & -0.073 & $\downarrow$ \\
\hline Nagaland & 0.234 & Low & 0.247 & Low & 0.013 & $\rightarrow$ \\
\hline Odisha & 0.456 & High & 0.570 & High & 0.114 & $\rightarrow$ \\
\hline Sikkim & 0.488 & High & 0.492 & High & 0.004 & $\rightarrow$ \\
\hline Tripura & 0.263 & Low & 0.269 & Low & 0.006 & $\rightarrow$ \\
\hline West Bengal & 0.383 & Medium & 0.394 & Medium & 0.011 & $\rightarrow$ \\
\hline South zone & 0.408 & Medium & 0.389 & Medium & -0.019 & $\leftarrow$ \\
\hline Andhra Pradesh & 0.454 & High & 0.516 & High & 0.062 & $\rightarrow$ \\
\hline Karnataka & 0.567 & High & 0.596 & High & 0.029 & $\rightarrow$ \\
\hline Kerala & 0.545 & High & 0.529 & High & -0.015 & $\leftarrow$ \\
\hline Puducherry* & 0.466 & High & 0.331 & Medium & -0.135 & $\downarrow$ \\
\hline Tamil Nadu & 0.180 & Low & 0.189 & Low & 0.009 & $\rightarrow$ \\
\hline Telangana & 0.392 & Medium & 0.341 & Medium & -0.051 & $\leftarrow$ \\
\hline India & 0.358 & Medium & 0.377 & Medium & 0.020 & $\rightarrow$ \\
\hline \multicolumn{7}{|c|}{$\begin{array}{l}\text { Note: } \uparrow \text { Upward transition from a lower category to higher; } \rightarrow \text { No change in category but MHSI value increased; } \rightarrow \\
\text { No change in category but MHSI value decreased; } \downarrow \text { Downward transition from a higher category to lower. }\end{array}$} \\
\hline \multicolumn{7}{|c|}{ *Denotes Union Territory (UT). } \\
\hline
\end{tabular}

The transition of states across different MHSI categories based on the MHSI index values in the base year and reference year have also been presented through geo-spatial maps in the Figure 3 (Figure 3A for scenario I and Figure $3 \mathrm{~B}$ for scenario IV).

\section{Discussion}

Out of the 15 maternal health service indicators, institutional delivery (INC indicator), immunization against tetanus, ANC check-ups and IFA supplementation (ANC indicators) recorded relatively higher mean percentage (more than $70 \%$ ) coverage at all India level for three years (2017-18 to 2019-20). The maternal health care services like institutional delivery and antenatal care coverage in India observed substantial progress in the past two decades with the implementation of plethora of targeted government driven programmes such as National Health Mission (NHM), Maternity Benefit programmes like Janani Suraksha Yojana(JSY), Pradhan Mantri Surakshit Matritva Abhiyan (PMSMA) and Pradhan Mantri Matru Vandana Yojana (PMMVY) to name a few $[4,5,29]$. Recently launched 'Anemia 
Mukt Bharat' programme has given prime importance to IFA supplementation for pregnant women, which is a highly probable reason for enhanced IFA coverage [30]. However, national mean percentage coverage of some of the indicators of maternal health service coverage is quite perturbing, such as; screening for diabetes (ANC indicator), SBA attended home deliveries, c-section delivery and treatment for obstetric complications (all INC indicators) as they recorded relatively low mean percentage (around 30\%) coverage across the country. Some state specific studies recorded prevalence of gestational diabetes ranged between $9.89-35 \%$ [31-35], which is quite alarming. In this regard, in compliance with the recommendations of WHO and International Association of Diabetes and Pregnancy Study Group (IADPSG), India requires region specific efforts to expand its coverage of screening for diabetes among pregnant women [34]. Though the present study observed lower mean percentage coverage for c-section delivery across India, nevertheless the growth rate of c-section delivery in India has doubled during 2005-06 to 2015-16 [36]. Low socio-economic status, awareness of available schemes, distance to health facility, absence of transport, and social cultural norms can be identified for preference of home delivery and related maternal complications in India [37-40].

Both southern and western zones of India have outperformed the other zones on the coverage of a number of maternal health indicators. South zone, particularly have performed sizable well with respect to institutional deliveries, IFA supplementation, ANC check-ups and screening for HIV. [41-44]. The states of Kerala, Tamil Nadu, Karnataka and Andhra Pradesh from south zone are the front runners in the overall 'Sustainable Development Goals' (SDGs) with relatively high SDG index scores, which has remarkably influenced their coverage and receipt of health care services such as institutional care and antenatal care coverage [45]. Consistently high HIV prevalence districts were clustered mainly in the south zone of the country [46], therefore, it is expected to have high percentage coverage in screening for HIV as a preventive measure. Furthermore, most of the states from south zone are known for its remarkable performance in literacy rates, particularly in female literacy [47], which can be a possible reason for increased awareness of HIV screening among south zone population. West zone particularly has recorded a substantial high coverage for immunization against tetanus, ANC registration, calcium supplementation and anemia treatment coverage. Effective planning and management of resources, re-establishment of outreach services, community links, supportive supervision and monitoring are the possible facilitating factors of immunization services including tetanus [48]. State governments of Gujarat, Chhattisgarh and Madhya Pradesh from west zone has collaborated with WHO for calcium supplementation to pregnant women [49] possibly the reason for high 'calcium supplementation' coverage in west zone.

North zone recorded lowest coverage for indicators particularly with respect to screening for HIV and SBA attended home deliveries. Low female literacy and rigid socio-cultural factors of majority of states from the north zone may have resulted in low SBA attended home deliveries [47]. However, Uttar Pradesh and Rajasthan from north zone are observed to be the states which require highest need for 'Prevention of Maternal to Child Transmission' (PMCTC) of HIV [50] and therefore demands high coverage in screening for HIV among pregnant women. East \& north east zone has underperformed on a number of indicators, specifically for screening pregnant women for diabetes, c-section delivery and treatment for obstetric complications. Low female literacy rate [47] and high proportion of tribal population [51] are expected to account for low c-section delivery rates in this zone. Majority of states from east \& north east zone recorded low prevalence of diabetes in a nationwide study [52], making it a likely cause for low diabetes screening coverage. Inaccessible regional terrain, poor transportation facilities, availability of prompt medical services and behavioural factors (tobacco and alcohol use) are significantly associated with low treatment coverage for obstetric complications [53]. 
The methodology adopted in the present study for data normalization and construction of MHSI is primarily based on United Nations Development Programme (UNDP)'s procedure to compute Human Development Index (HDI) [54], which is highly rigorous and standardized. Further, the study generated MHSI scores based on the choice of arithmetic mean and geometric mean approach for aggregating the 15 indicators into one composite index. Geometric mean approach (used in scenario IV) has an advantage over arithmetic mean approach (used in scenario I) as it is less affected by skewed data and extreme values, thereby integrating the overall balance in the data distribution [28]. However, usage of arithmetic mean is more suitable in those cases where the data normalization is carried from the observed values of the data distribution [55]. Therefore, comparison of index values across these two different approach-based scenarios are redundant in nature. The authors clarify that the study elucidates the comparison of MHSI values across two time periods (base year and reference year) within a given scenario and not across the two scenarios. Construction of MHSI for these two particular scenarios, facilitates the identification of those common states/union territories/regions, which have transitioned form a lower to higher category of maternal health service coverage or vice versa. The earlier attempts to measure maternal health service coverage have been limited and narrow in their approach. Composite Coverage Index (CCl), which comprised essential health interventions of RMNCH continuum of care [56], included only two indicators i.e., 'skilled birth attendant' and 'antenatal care coverage' under the domain of maternal and new born care. In contrast, the present study specifically emphasized on maternal health service coverage rather than considering the consolidated RMNCH coverage as studied in the previous literature [19-21, 56, 57].

Different states/UTs/zones in India have performed variedly as far as MHSI scores are concerned. The UTs of Dadra \& Nagar Haveli and Chandigarh showed upward transition of MHSI category in both scenarios (I and IV). Dadra \& Nagar Haveli transitioned from medium to high category and that of Chandigarh showed low to medium category. This might be likely due to concentrated efforts of respective governments and also partly because these UTs are the front runners or performers in specific SDGs related to poverty, health, quality education and economic growth [45]. The state of Maharashtra and Assam showed an upward transition in both scenarios from medium to high MHSI category, while Jharkhand showed upward transition from low to medium category. Assam and Jharkhand have remarkably improved its maternal health outcomes and have recently been accorded a position of 'achiever' in a health index released by National Institution for Transforming India (NITI) Aayog, which is Indian government's apex think tank [58]. While, the state of Maharashtra is a frontrunner across various dimensions of NITI Aayog's health index. On the other hand, the state of Mizoram and the UT of Puducherry displayed downward transition in both scenarios. This might be due to relatively less coverage on number of indicators like IFA supplementation [59], diabetes screening $[52,60]$, ANC check-ups and treatment of obstetric complications. Out of the 4 zones, only the west zone transitioned upwards in the reference year from the medium to high MHSI category. The state of Goa and Maharashtra and the UT of Dadra and Nagar Haveli from the west zone performed substantially well, which gave an upsurge in the MHSI scores of the west zone. None of the zones showed downward transition across two time points for both the methodological scenarios. Region/state/UT specific health interventions are required to be undertaken to target low coverage indicators of maternal health for bolstering their performance to achieve positive incremental changes in maternal health outcomes over time.

The present study faces some limitations. Due to limited data availability at sub-national level, the analysis pertains to a short time span of three years (2017-18 to 2019-20), hence inferences need to be drawn with caution. The incremental changes in the maternal health service coverage reflect only the preliminary estimates and therefore should not be used to draw inferences for long term policy purpose. More time series data is required to confirm and substantiate the inferences of these short time series-based results. This leaves a lot of scope for future research to undertake longitudinal analysis concerning the theme of the present study. Though, the composite 'Maternal Health

Page 17/28 
service Index' computed in the study involves a set of 15 indicators, which is relatively larger than the previous studies, however; data on only one indicator (postpartum check-up) was available and classified under the domain of postnatal care, which makes this domain under-represented for constructing the index. Government of India has initiated a number of schemes especially for nutritional interventions of pregnant and lactating women [61, 62] for antenatal and postnatal care. In this light, besides postpartum check-up, which is a globally recognised indicator [63], data on more indicators like nutritional support, screening for psychological wellbeing after delivery [64] and alike should be disseminated on government portal for better representation of the PNC domain, which is an important food for thought for a revised version of this novel index in future. Although, the study envisioned to examine each and every state as well as union territories, however the two union territories of Daman \& Diu and Lakshadweep were excluded from the analysis as they both registered missing values for more than one specific year on a particular maternal health indicator, thereby rendering the standard imputation techniques and extrapolation/ interpolation procedures inapplicable. Nevertheless, the present study has some strong points and strengths to offer. The novel 'Maternal Health Service Coverage Index' envisaged and constructed in the present study is a pioneer attempt to comprehensively quantify the sub-national coverage of maternal health service in India by including within its ambit 15 indicators spread across each of the three domains of antenatal care, intranatal care and postnatal care. No published study has elucidated the measurement of maternal health service coverage in terms of broad spectrum of antenatal, intranatal and postnatal care coverage till date in India, though these domains hold prime importance and are widely valued by the reputed international and national organizations $[3,9,65]$. There is wide scope of usage for this unique 'composite index' as it provides a concise and quantified information of a complex and multifaceted facts representing maternal health service coverage, which makes it easy to communicate and report for the policy purpose [66] at sub-national level in the Indian setting. The study has further mapped and categorized India into different zones, thereby providing a snapshot of low, medium and high maternal health service coverage states/union territories and regions. Furthermore, the study by considering a nationally representing data published by Indian government, have facilitated the comparison of the maternal health service coverage performance at the sub-national level across different time points, which has allowed to identify which states/union territories and regions have transitioned from lower to a higher maternal health service coverage category and vice versa.

\section{Conclusion}

Measuring and mapping of maternal health service coverage at sub-national level can have significant policy implications for a developing country like India, which is making rapid strides in healthcare sector transformation. A composite summary measure to reflect the coverage of maternal health service can momentously help India to identify low coverage maternal health service indicators and recognize lagged zones, thereby warranting the concentrated programmatic and clinical efforts to detect, examine and target specific characteristics of a particular state/UT/region that has significant effect on maternal health service coverage. The accessibility, availability and utilization of quality driven maternal health services are key for survival and wellbeing of both mother and the child. A regular longitudinal and extensive monitoring of the performance of states with regard to essential maternal health services shall induce the country towards achieving the SDG target of improved maternal and child health outcomes.

\section{Abbreviations}




\begin{tabular}{|c|c|}
\hline ANC: & Antenatal care \\
\hline CCl: & Composite Coverage Index \\
\hline CGI: & Coverage Gap Index \\
\hline DNH: & Dadra \& Nagar Haveli \\
\hline HDI: & Human Development Index \\
\hline HIV: & Human immunodeficiency Virus \\
\hline HMIS: & Health Management Information System \\
\hline IADPSG: & International Association of Diabetes and Pregnancy Study Group \\
\hline IFA: & Iron Folic Acid \\
\hline INC: & Intranatal care \\
\hline JSY: & Janani Suraksha Yojana \\
\hline MHSI: & Maternal Health Service coverage Index \\
\hline MoHFW: & Ministry of Health and Family Welfare \\
\hline NHM: & National Health Mission \\
\hline NITI: & National Institution for Transforming India \\
\hline PMCTC: & Prevention of Maternal to Child Transmission \\
\hline PMMVY: & Pradhan Mantri Matru Vandana Yojana \\
\hline PMSMA: & Pradhan Mantri Surakshit Matritva Abhiyan \\
\hline PNC: & Postnatal care \\
\hline RMNCH: & Reproductive, Maternal, New born and Child Health \\
\hline RMNCH+A: & Reproductive, Maternal, Newborn, Child and Adolescent Health \\
\hline SBA: & Skilled Birth Attendant \\
\hline SDG: & Sustainable Development Goals \\
\hline UNDP: & United Nations Development Programme \\
\hline UT: & Union Territories \\
\hline WHO: & World Health Organization \\
\hline
\end{tabular}

\section{Declarations}

\section{Ethics approval and consent to participate}

The study is purely based on secondary data and does not involve any interaction with the participants/human subjects. The data used for the study is freely available and accessible to the general public through the web based HMIS portal, which is maintained by the Indian Ministry of Health and Family Welfare (https://hmis.nhp.gov.in/). Therefore, no ethics approvals were required for this study. 
The authors assert that all methods carried out in the current study comply with relevant guidelines and regulations.

\section{Consent for publication}

Not applicable

\section{Availability of data and materials}

The dataset generated and/or analysed during the current study are available in the Mendeley data repository, DOI:10.17632/ngtpyv4zws.1, https://data.mendeley.com/datasets/ngtpyv4zws/1.

\section{Competing interest}

The authors declared that they have no competing interest.

\section{Funding}

No specific grant from funding agencies either in the public, commercial, or not-for-profit sectors was received for this research.

\section{Author's contributions}

TK \& KJ conceived the study. TK, VR and MG contributed in identifying indicators of maternal health service coverage and categorizing the indicators into different domains of maternal health service coverage. KJ \& DS extracted the data and rechecked for possible errors in the dataset. KJ \& TK performed the data analysis and contributed in the interpretation of the results. KJ prepared the first draft of the manuscript and TK \& DS thoroughly revised, conducted its final review and approved the final version of the manuscript. All authors reviewed the manuscript.

Corresponding author: Correspondence to KP Junaid

\section{Acknowledgements}

Not applicable

\section{Authors information}

Department of Community Medicine and School of Public Health, Post Graduate Institute of Medical Education and Research (PGIMER), Chandigarh, India.

Tanvi Kiran, KP Junaid ${ }^{\star}$, Vineeth Rajagopal, Madhu Gupta and Divya Sharma

\section{References}

1. Goal 3 | Department of Economic and Social Affairs. https://sdgs.un.org/goals/goal3. Accessed 11 Sep 2021.

2. Maternal Health Programme. In: NRHM Annual report 2012-2013. NRHM; 2013. p. 49-58.

3. Ministry of Health and Family Welfare. Guidelines for Antenatal Care and Skilled Attendance Antenatal Care and Skilled Attendance at Birth by ANMs/LHVs/SNs. 2010.

4. Salve HR, Charlette L, Kankaria A, Rai SK, Krishnan A, Kant S. Improving access to institutional delivery through Janani Shishu Suraksha Karyakram: Evidence from rural Haryana, North India. Indian J Community Med. 
2017;42:73-6.

5. Sinha P, Gunagi PR, Viveki RG, Kamble M, Halki S. Utilization of antenatal services under Pradhan Mantri Surakshit Matritva Abhiyan in rural area of North Karnataka: a cross-sectional study. Natl J Res Community Med. 2019;8:184.

6. Nawale AY, Jadhav P, Hirve S, Butla M, Boinwad S, Khedekar S, et al. A study to assess the knowledge regarding Pradhan Mantri Matru Vandana Yojna among antenatal mothers of selected area of Pune city. Eur J Mol Clin Med. 2020;07:10.

7. NHM:: National Health Mission. https://nhm.gov.in/index4.php?lang=1\&level=0\&linkid=445\&lid=38. Accessed 15 Dec 2021.

8. Kerber KJ, de Graft-Johnson JE, Bhutta ZA, Okong P, Starrs A, Lawn JE. Continuum of care for maternal, newborn, and child health: from slogan to service delivery. Lancet. 2007;370:1358-69.

9. WHO. WHO recommendations on antenatal Care for a Positive Pregnancy Experience. 2016. https://apps.who.int/iris/bitstream/handle/10665/259947/WHO-RHR-18.02-eng.pdf?sequence=1.

10. WHO. Intrapartum care for a positive childbirth experience. Geneva: World Health Organization; 2018. http://apps.who.int/iris/bitstream/10665/260178/1/9789241550215-eng.pdf? ua=1\%0Ahttp://www.who.int/reproductivehealth/publications/intrapartum-care-guidelines/en/.

11. Chattopadhyay A, Ghosh S. Population dynamics in eastern India and Bangladesh: Demographic, health and developmental issues. Singapore: Springer Singapore; 2020.

12. Poudel S, Ghimire PR, Upadhaya N, Rawal L. Factors associated with stillbirth in selected countries of South Asia: A systematic review of observational studies. PLoS One. 2020;15 9 September:1-12. doi:10.1371/journal.pone.0238938.

13. Blencowe H, Cousens S, Oestergaard MZ, Chou D, Moller AB, Narwal R, et al. National, regional, and worldwide estimates of preterm birth rates in the year 2010 with time trends since 1990 for selected countries: A systematic analysis and implications. Lancet. 2012;379:2162-72.

14. Patel A, Prakash AA, Pusdekar Y V., Kulkarni H, Hibberd P. Detection and risk stratification of women at high risk of preterm birth in rural communities near Nagpur, India. BMC Pregnancy Childbirth. 2017;17. doi:10.1186/S12884-017-1504-4.

15. Majella M, Sarveswaran G, Krishnamoorthy Y, Sivaranjini K, Arikrishnan K, Kumar S. A longitudinal study on high risk pregnancy and its outcome among antenatal women attending rural primary health centre in Puducherry, South India. J Educ Health Promot. 2019;8. doi:10.4103/JEHP.JEHP_144_18.

16. Montgomery AL, Fadel S, Kumar R, Bondy S, Moineddin R, Jha P. The effect of health-facility admission and skilled birth attendant coverage on maternal survival in India: A case-control analysis. PLoS One. 2014;9:1-10.

17. Prinja S, Bahuguna P, Gupta R, Sharma A, Rana SK. Coverage and Financial Risk Protection for Institutional Delivery: How Universal Is Provision of Maternal Health Care in India ? 2015;771 Usd 229:1-15.

18. WHO. WHO recommendations on Postnatal care of the mother and newborn. Geneva; 2013. http://apps.who.int/iris/bitstream/10665/97603/1/9789241506649_eng.pdf.

19. Awasthi A, Pandey CM, Chauhan RK, Singh U. Disparity in maternal, newborn and child health services in high focus states in India: A district-level cross-sectional analysis. BMJ Open. 2016;6:1-9.

20. Rios Quituizaca P, Gatica-Domínguez G, Nambiar D, Ferreira Santos JL, Brück S, Vidaletti Ruas L, et al. National and subnational coverage and inequalities in reproductive, maternal, newborn, child, and sanitary health interventions in Ecuador: a comparative study between 1994 and 2012. Int J Equity Health. 2021;20:1-14. 
21. Panda BK, Kumar G, Awasthi A. District level inequality in reproductive, maternal, neonatal and child health coverage in India. BMC Public Health. 2020;20:1-10.

22. NITI Aayog. Evaluation Repor On Efficacy of Minimum Support Prices (MSP) on Farmers. New Delhi; 2016. http://niti.gov.in/writereaddata/files/writereaddata/files/document_publication/MSP-report.pdf.

23. Junaid K, Kiran T, Rajagopal V, Gupta M, Sharma D. Maternal Health Service Coverage in India. Mendeley data. $2021 ; 1$.

24. Sharma A, Prinja S, Aggarwal AK. Comprehensive measurement of health system performance at district level in India: Generation of a composite index. Int J Health Plann Manage. 2019;34:e1783-99.

25. Graham JW. Missing data analysis: Making it work in the real world. Annu Rev Psychol. 2009;60:549-76.

26. Hirakawa T, Hatogai J. A Study of Missing Value Imputation in Business Surveys: The Case of the Short-Term Economic Survey of Enterprises in Japan (Tankan). Tokyo; 2013.

https://www.boj.or.jp/en/research/wps_rev/wps_2013/data/wp13e09.pdf.

27. Mathew CK, Dutta U, Narayanan A, Jalodia S. Public Affairs Index- Governance in the States of India. Bangalore; 2017.

28. UNDP. Training Material for Producing National Human Development Reports. Hum Dev Rep Off. 2015; March:137.

29. Ali B, Dhillon P, Mohanty SK. Inequalities in the utilization of maternal health care in the pre- and post-National Health Mission periods in India. J Biosoc Sci. 2019;:1-15.

30. 6 Interventions of the Anemia Mukt Bharat Programme. https://anemiamuktbharat.info/home/interventions/. Accessed 18 Dec 2021.

31. Chanda S, Dogra V, Hazarika N, Bambrah H, Sudke AK, Vig A, et al. Prevalence and predictors of gestational diabetes mellitus in rural Assam: a cross-sectional study using mobile medical units. BMJ Open. 2020;10. doi:10.1136/BMJOPEN-2020-037836.

32. Hussain T, Das S, Parveen F, Samanta P, Bal M, Yadav V, et al. Prevalence, risk factors and morbidities of gestational diabetes among pregnant women attending a hospital in an urban area of Bhubaneswar, Odisha. J Fam Med Prim care. 2020;9:5327. doi:10.4103/JFMPC.JFMPC_869_20.

33. Singh T, Vanlalhruaii, Ranabir S, Prasad L, Singh N. Prevalence of gestational diabetes mellitus and its correlation with blood pressure in Manipuri women. Indian J Endocrinol Metab. 2013;17:957. doi:10.4103/22308210.122597.

34. Arora GP, Thaman RG, Prasad RB, Almgren P, Brøns C, Groop LC, et al. Prevalence and risk factors of gestational diabetes in Punjab, North India: results from a population screening program. Eur J Endocrinol. 2015;173:25767. doi:10.1530/EJE-14-0428.

35. Mohan MA, Chandrakumar A. Evaluation of prevalence and risk factors of gestational diabetes in a tertiary care hospital in Kerala. Diabetes Metab Syndr. 2016;10:68-71. doi:10.1016/J.DSX.2015.09.002.

36. Kumar P, Dhillon P. Household- and community-level determinants of low-risk Caesarean deliveries among women in India. J Biosoc Sci. 2021;53:55-70. doi:10.1017/S0021932020000024.

37. Sarkar A, Kharmujai OM, Lynrah W, Suokhrie NU. Factors influencing the place of delivery in rural Meghalaya, India: A qualitative study. J Fam Med Prim Care. 2018;7:98. doi:10.4103/JFMPC.JFMPC_45_17.

38. Gorain A, Barik A, Chowdhury A, Rai RK. Preference in place of delivery among rural Indian women. PLoS One. 2017;12. doi:10.1371/JOURNAL.PONE.0190117. 
39. Patel R, Marbaniang SP, Srivastava S, Kumar P, Chauhan S. Why women choose to deliver at home in India: a study of prevalence, factors, and socio-economic inequality. BMC Public Health. 2021;21:1-14. doi:10.1186/S12889-021-11779-5/TABLES/3.

40. Agrawal N, Tiwari A. Determinants of Home Delivery among Mothers in Urban and Rural Vadodara District, Gujarat, India. Indian J Community Med. 2020;45:159. doi:10.4103/IJCM.IJCM_289_19.

41. Kothavale A, Meher T. Level of completion along continuum of care for maternal, newborn and child health services and factors associated with it among women in India: a population-based cross-sectional study. 2021;21:731. doi:10.1186/s12884-021-04198-2.

42. Alkenbrack S, Chaitkin M, Zeng W, Couture T, Sharma S. Did Equity of Reproductive and Maternal Health Service Coverage Increase during the MDG Era? An Analysis of Trends and Determinants across 74 Low- and MiddleIncome Countries. PLoS One. 2015;10:e0134905. doi:10.1371/JOURNAL.PONE.0134905.

43. Marten R, Mclntyre D, Travassos C, Shishkin S, Longde W, Reddy S, et al. An assessment of progress towards universal health coverage in Brazil, Russia, India, China, and South Africa (BRICS). Lancet. 2014;384:2164-71.

44. Barman B, Roy A, Zaveri A, Saha J, Chouhan P. Determining factors of institutional delivery in India: A study from National Family Health Survey-4 (2015-16). Clin Epidemiol Glob Heal. 2020;8:1335-40. doi:10.1016/J.CEGH.2020.05.007.

45. NITI. SDG India- Index \& Dashboard2020-21: Partnership in the Decade of Action. New Delhi; 2021. https://www.niti.gov.in/writereaddata/files/SDG_3.0_Final_04.03.2021_Web_Spreads.pdf. Accessed 13 Dec 2021.

46. Joshi RK, Mehendale SM. Determinants of consistently high HIV prevalence in Indian Districts: A multi-level analysis. PLoS One. 2019;14:1-14.

47. Saurabh S, Sarkar S, Pandey DK. Female Literacy Rate is a Better Predictor of Birth Rate and Infant Mortality Rate in India. J Fam Med Prim Care. 2013;2:349. doi:10.4103/2249-4863.123889.

48. Montgomery JP, Ganguly P, Carlson BF, Shrivastwa N, Boulton ML. An evaluation of immunization services, using the reaching every district criteria, in two districts of Gujarat, India. Glob Heal Res Policy. 2018;3:1-7. doi:10.1186/S41256-018-0060-4/FIGURES/1.

49. Action - Nutrition International - India - Maternal Nutrition Program - Iron and folic acid supplementation Pregnant women (PW) | Global database on the Implementation of Nutrition Action (GINA). https://extranet.who.int/nutrition/gina/en/node/26263. Accessed 18 Dec 2021.

50. National AIDS Control Organisation, ICMR-National Institute of Medical Statistics. INDIA HIV ESTIMATES 2020: Technical Brief. New Delhi:; 2021. http://naco.gov.in/sites/default/files/India HIV Estimates 2020_Web_Version.pdf. Accessed 19 Dec 2021.

51. Census of India: T 00-005: Total Population, Population of Scheduled Castes and Scheduled Tribes and their proportions to the total population. https://censusindia.gov.in/Tables_Published/A-Series/ASeries_links/t_00_005.aspx. Accessed 19 Dec 2021.

52. Anjana RM, Deepa M, Pradeepa R, Mahanta J, Narain K, Das HK, et al. Prevalence of diabetes and prediabetes in 15 states of India: results from the ICMR-INDIAB population-based cross-sectional study. lancet Diabetes Endocrinol. 2017;5:585-96. doi:10.1016/S2213-8587(17)30174-2.

53. Kumar P, Srivastava S, Maurya C, Dhillon P. An assessment of the role of socio-economic, maternal and service utilization factors in increasing self-reported maternal complications in India. BMC Pregnancy Childbirth. 2021;21:1-13. doi:10.1186/S12884-021-03997-X/TABLES/3.

54. UNDP. Technical Notes on calculating human development indices. New York; 2010. 
55. OECD. Handbook on Constructing Composite Indicators: Methodology and User guide. 2008.

56. Equity Analysis Group. Mind the gap: equity and trends in coverage of maternal, newborn, and child health services in 54 Countdown countries. 2008;371:1259-67.

57. Rai RK. District level coverage gap in Maternal, Newborn and Child Health care services in India. J Epidemiol Glob Health. 2013;2:221-4. doi:10.1016/j.jegh.2012.12.004.

58. NITI. HEALTHY STATES PROGRESSIVE INDIA Report on the Ranks of States and Union Territories HEALTH INDEX. 2019. http://social.niti.gov.in/. Accessed 19 Dec 2021.

59. Halli SS, Biradar RA. Is Distribution a Problem in Iron-Folic Acid Consumption in India? An Exploration of District Level Household Survey. Open Fam Stud J. 2020;12:34-9.

60. Venugopal V, Selvaraj K, Majumdar A, Chinnakali P, Roy G. Opportunistic screening for diabetes mellitus among adults attending a primary health center in Puducherry. Int J Med Sci Public Heal. 2015;4:1206. doi:10.5455/IJMSPH.2015.03032015238.

61. PMMVY | Ministry of Women \& Child Development. https://wcd.nic.in/schemes/pradhan-mantri-matru-vandanayojana. Accessed 19 Dec 2021.

62. 62.:: POSHAN Abhiyaan - Ministry of Women and Child Development, Government of India :: https://icdswcd.nic.in/nnm/home.htm. Accessed 19 Dec 2021.

63. Moran AC, Kerber K, Sitrin D, Guenther T, Morrissey CS, Newby H, et al. Measuring Coverage in MNCH: Indicators for Global Tracking of Newborn Care. PLOS Med. 2013;10:e1001415. doi:10.1371/JOURNAL.PMED.1001415.

64. Cole JCM, Olkkola M, Zarrin HE, Berger K, Moldenhauer JS. Universal Postpartum Mental Health Screening for Parents of Newborns With Prenatally Diagnosed Birth Defects. J Obstet Gynecol neonatal Nurs JOGNN. 2018;47:84-93. doi:10.1016/J.JOGN.2017.04.131.

65. National Collaborating Centre for Women's and Children's Health. Antenatal care routine care for the healthy pregnant woman. 2nd edition. London: RCOG Press; 2008.

66. Saltelli A. Composite indicators between analysis and advocacy. Soc Indic Res. 2007;81:65-77.

\section{Figures}




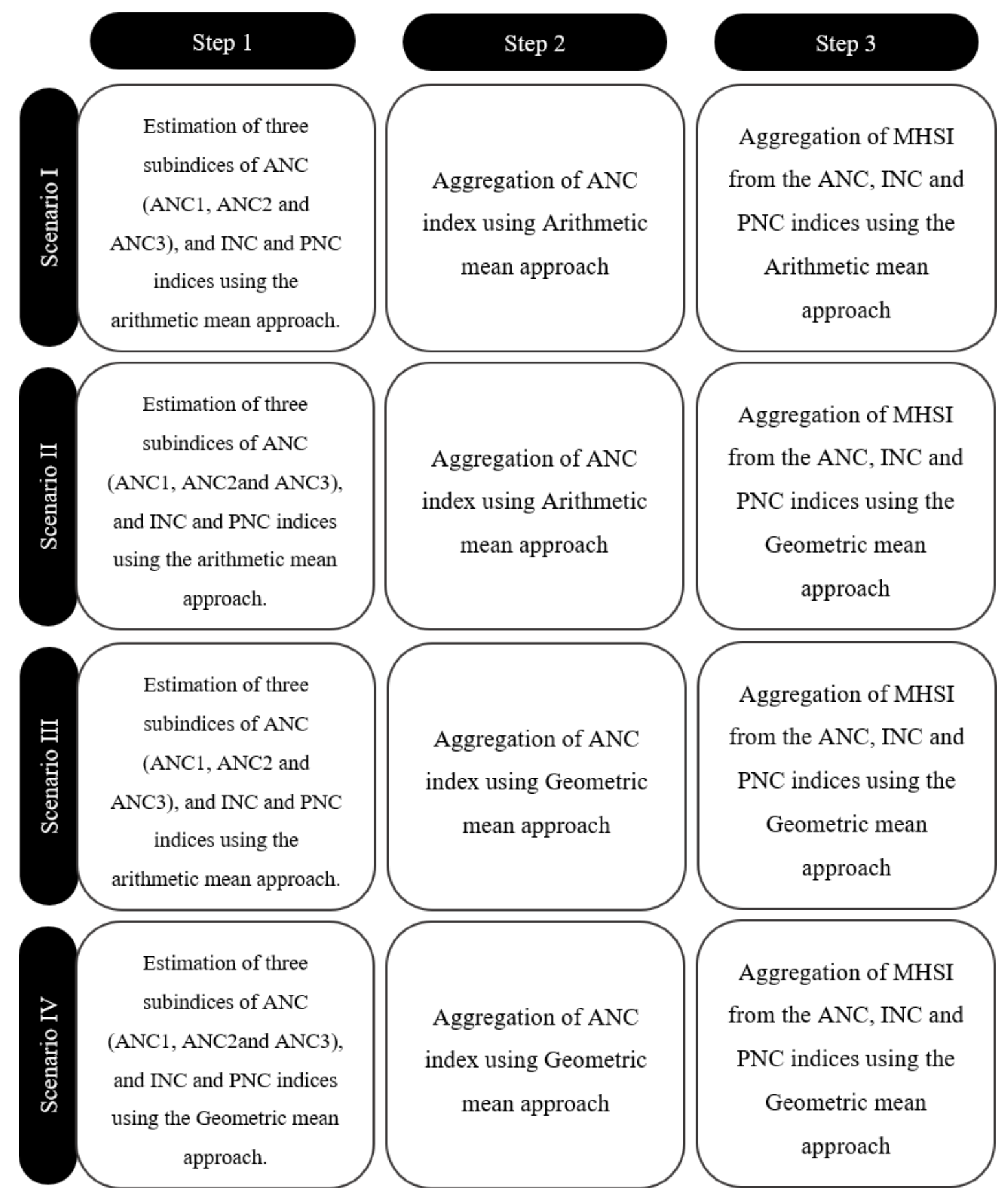

Figure 1

Different scenarios of the aggregation of domains and subdomains of MHSI 
ANC Registration

$$
\text { Post Partum Checkup } \quad \mathbf{1 0 0 . 0 0} \quad \text { ANC Check-ups }
$$

Treatment for obstetric complications

80.00

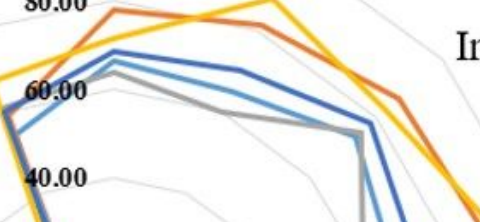

C-Section deliveries

SBA attended home deliveries

Screening for HIV

Screening for Syphilis
Immunization against Tetanus

IFA Supplementation

Anaemia treatment coverage

Calcium supplementation

$\begin{array}{ll}\text {-North Zone } & \text { - East\&North East Zone }\end{array}$

Figure 2

Radar Diagram exhibiting the extent of Maternal health service coverage in India across different zones over the period 2017-2020 


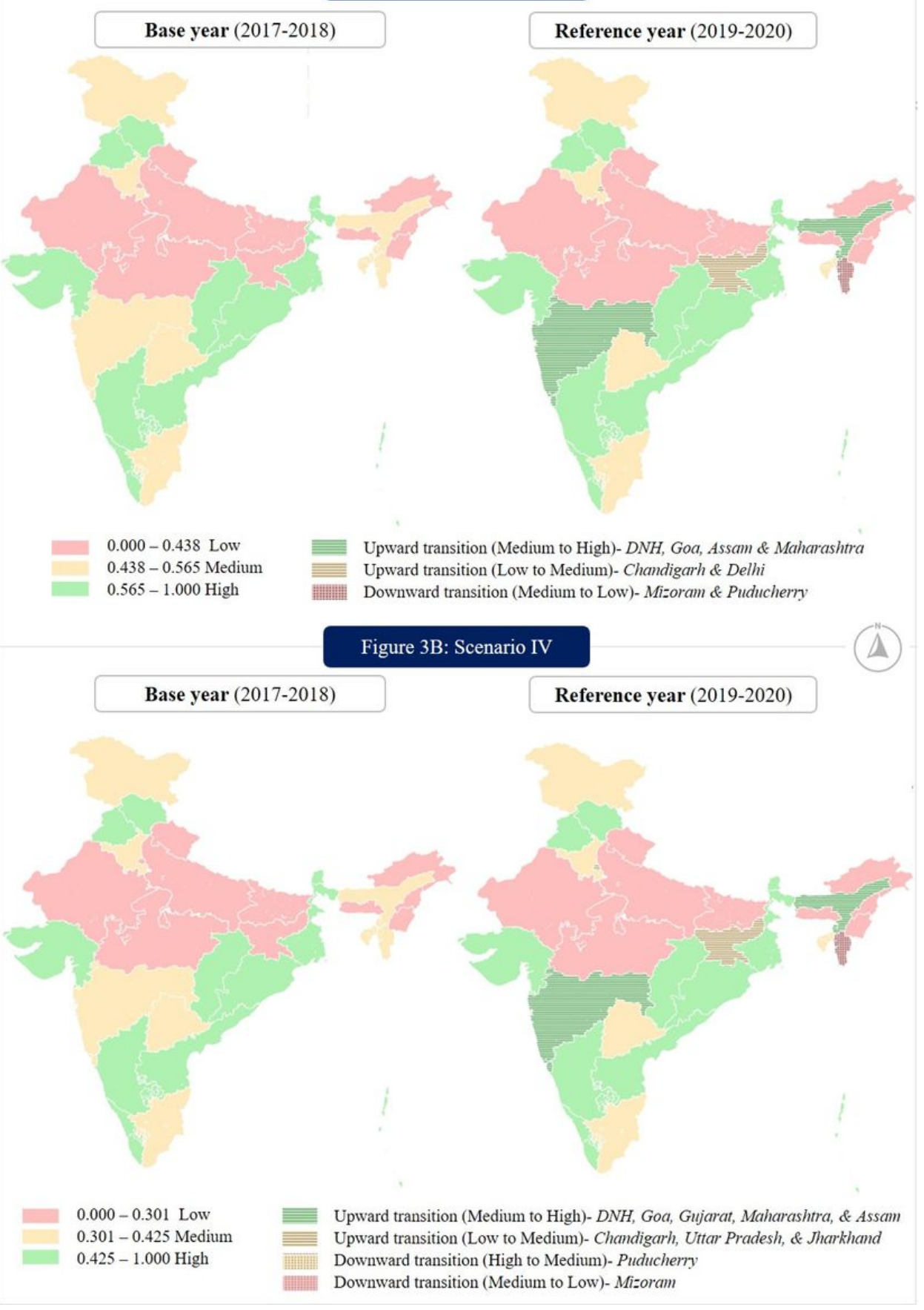

\section{Figure 3}

Extent of maternal health service coverage and transition of Indian states and Union territories for scenario I and scenario IV.

\section{Supplementary Files}

This is a list of supplementary files associated with this preprint. Click to download.

- Additionalfile1.pdf 
- Additionalfile2.pdf

- Additionalfile3.pdf

- Additionalfile4.pdf 